\title{
SUSTENTABILIDADE DE AGROECOSSISTEMAS DE PRODUÇÃO DE MANDIOCA DO AGRESTE PARAIBANO SOB A ÓTICA DO BIOGRAMA
}

\section{AGROECOSYSTEMS SUSTAINABILITY OF CASSAVA PRODUCTION OF PARAÍBA RURAL AREA FROM THE PERSPECTIVE OF BIOGRAM}

\author{
Valdenildo Pedro da Silva \\ Instituto Federal de Educação, Ciência e Tecnologia Rio Grande do Norte - \\ Natal - RN - Brasil \\ Ranielle Freire da Silva \\ Instituto Federal de Educação, Ciência e Tecnologia Rio Grande do Norte - \\ Natal - RN - Brasil \\ Anieres Barbosa da Silva \\ Universidade Federal da Paraíba - João Pessoa - PB - Brasil \\ Leci Martins Menezes Reis \\ Instituto Federal de Educação, Ciência e Tecnologia Rio Grande do Norte - \\ Natal - RN - Brasil
}

\begin{abstract}
Resumo: A modernização da agricultura, resultante da revolução verde, ocorreu por meio de várias inovações tecnológicas, como fertilizantes solúveis, agroquímicos, máquinas agrícolas e sementes geneticamente modificadas, visando o aumento da produção de alimentos. Todavia, o uso indiscriminado dessas novações pelos agricultores tem posto em evidência inúmeros problemas socioambientais, comprometendo o sistema agrícola produtivo. Essa realidade de inovações tecnológicas e de obstáculos socioambientais também vem sendo vivenciada pela produção de mandioca do agreste paraibano. Por isso, o presente estudo procurou avaliar a sustentabilidade de agroecossistemas de produção de mandioca (Manihot esculenta (rantz) da Mesorregião do Agreste da Paraíba, utilizando o método do Índice de Desenvolvimento Sustentável $\left(\mathrm{S}^{3}\right)$ e sua representação gráfica, o Biograma. Os resultados do trabalho mostraram que há diferenças de sustentabilidade entre os agroecossistemas dos municípios investigados, dos quais os de Araçagi apresentaram
\end{abstract}


níveis estáveis de sustentabilidade, os de Araruna e de Bananeiras demonstraram níveis instáveis e os de Puxinanã evidenciaram-se, sustentavelmente, como os mais críticos. Conclui-se que, mesmo com os agroecossistemas do Município de Araçagi apresentando melhores níveis de sustentabilidade, quando comparados com os dos outros municípios avaliados, a produção de mandioca apresentou situações de insustentabilidade no tocante aos seus níveis de inovação tecnológica, rendimento médio da produção, terras em processo de erosão, escassez de água e ausência de participação social.

Palavras-chave: Sustentabilidade. Biograma. Produção de Mandioca. Agreste paraibano.

Abstract: Agriculture modernization resulting from green revolution occurred through means of diverse technological innovations as soluble fertilizers, pesticides, agricultural machinery and genetically modified seeds, aimed at increasing food production. However, the indiscriminate use of these innovations by farmers has been highlighted numerous environmental problems, affecting the productive agricultural system. This technological innovations reality and environmental obstacles, is also been experienced by cassava production in Paraíba rural area. Therefore, this study tried to assess the agroecosystems sustainability of cassava production (Manihot esculenta Crantz) of Paraíba Rural Mesoregion, using Sustainable Development Index $\left(\mathrm{S}^{3}\right)$ method, and its graphical representation, the Biogram. The results showed sustainability differences between the agroecosystems of investigated municipalities, of which Araçagi showed stable levels of sustainability, Araruna and Bananeiras demonstrated unstable levels, and Puxinanã showed the most critical sustainably level. It was concluded that, even the agroecosystems of Araçagi municipality showing better levels of sustainability, when compared with other municipalities assessed, cassava production showed unsustainability situations regarding its technological innovation levels, average yield of cassava production, land in erosion process, water scarcity and lack of social participation.

Keywords: Sustainability. Biogram. Cassava Production. Paraiba Rural Area.

\section{INTRODUÇÃO}

O processo de modernização da agricultura, originada pela revolução verde, resultou numa série de inovações tecnológicas, como fertilizantes e adubos agroquímicos, tratores e sementes geneticamente modificadas, visando o aumento da produtividade ou a produção de alimentos. Entretanto, esse novo modelo de produção agrícola, baseado na utilização de produtos agroquímicos ou industrializados, tem contribuído para aumentar os rendimentos agrícolas, mas vem elevando, também, os custos socioambientais de sustentabilidade de 
agroecossistemas intensivos ou familiares (ALTIERI, 2004; GLIESSMAN, 2009).

A produção de mandioca (Manihot esculenta Crantz) tem se modernizado tecnologicamente, mesmo que lentamente, no curso dos últimos 50 anos, e sendo cultivada em diversos estados brasileiros. Sua comercialização tem se dado em sua maioria na forma de farinha de mesa (MICHELS; CARVALHO; MENDONÇA, 2004). Essa cultura alimentar apresenta-se como uma grande fonte de carboidratos para a alimentação humana e animal. Todavia, a fécula (amido da mandioca), por ser mais versátil, tem despertado interesse cada vez maior como insumo industrial para diversos setores estratégicos, como o de celulose, o têxtil, o químico, o alimentício, dentre outros (LORENZI, 2003). No Brasil, a cadeia produtiva da mandioca apresenta-se, principalmente, ligada à economia tradicional e de subsistência (MICHELS; CARVALHO; MENDONÇA, 2004) e, em particular, no Estado da Paraíba, tem se destacado pela grande importância como fonte alimentar para a população e geradora de renda básica para os agricultores familiares (ALMEIDA; SANTOS, 2011).

A Mesorregião do Agreste da Paraíba tem se destacado por apresentar uma produção de mandioca em torno de 63\% (IBGE, 2006). Essa mesorregião é formada por 66 municípios que estão distribuídos em 08 microrregiões, das quais se destaca a Microrregião de Campina Grande como uma das principais produtoras de mandioca, responsável por 23,72\% da produção da Mesorregião e por, aproximadamente, 15\% da produção total da Paraíba, como pode ser observado pelos dados da Tabela 1.

Tabela 1. Quantidade produzida (toneladas) de mandioca no Estado da Paraíba e na Mesorregião do Agreste e suas Microrregiões

\begin{tabular}{|l|c|c|}
\hline $\begin{array}{l}\text { Paraíba } \\
\text { Agreste Paraibano }\end{array}$ & $\begin{array}{c}262.076 \\
\text { Microrregiões }\end{array}$ & $100 \%$ \\
\hline \multicolumn{2}{|c|}{ Curimataú Ocidental } & $63 \%$ \\
\hline Curimataú Oriental & 5.040 & $1,92 \%$ \\
\hline Esperança & 21.055 & $12,75 \%$ \\
\hline Brejo Paraibano & 7.200 & $4,37 \%$ \\
\hline Guarabira & 34.000 & $20,60 \%$ \\
\hline Campina Grande & 37.275 & $22,58 \%$ \\
\hline Itabaiana & 39.160 & $23,72 \%$ \\
\hline
\end{tabular}




\begin{tabular}{|l|l|l|}
\hline Umbuzeiro & 1.240 & $0,75 \%$ \\
\hline
\end{tabular}

Fonte: IBGE (2006).

A produção de mandioca, utilizando princípios da revolução verde, tem se disseminado nos diversos sistemas produtivos, modificando, até mesmo, os sistemas de produção familiar. A utilização indiscriminada de inovações tecnológicas pelos agricultores tem trazido inúmeros problemas sociais, como o êxodo rural, a falta de crédito para os agricultores, que não fazem uso do pacote tecnológico proposto pela revolução verde; e ambientais, como a contaminação das águas, dos alimentos, dos trabalhadores rurais, a destruição de florestas, a erosão do solo e a desertificação de algumas áreas (ELHERS, 2008).

Essa realidade socioambiental adversa tem se difundido por alguns agroecossistemas de produção de mandioca do agreste paraibano (Figura 1), mais precisamente, em quatro municípios pouco estudados e analisados, necessitando, assim, serem avaliados quanto aos seus níveis de desenvolvimento, uso e produção agrícolas, para que se investiguem os estados de sustentabilidade. Para operacionalização da sustentabilidade dos agroecossistemas, torna-se necessária a utilização de indicadores de sustentabilidade que são instrumentos que permitem, a partir da sua interpretação, definir a condição de um determinado sistema como sendo mais ou menos sustentável (COSTA, 2010). 
Figura 1. Mapa de localização das unidades de análise do Agreste da Paraíba

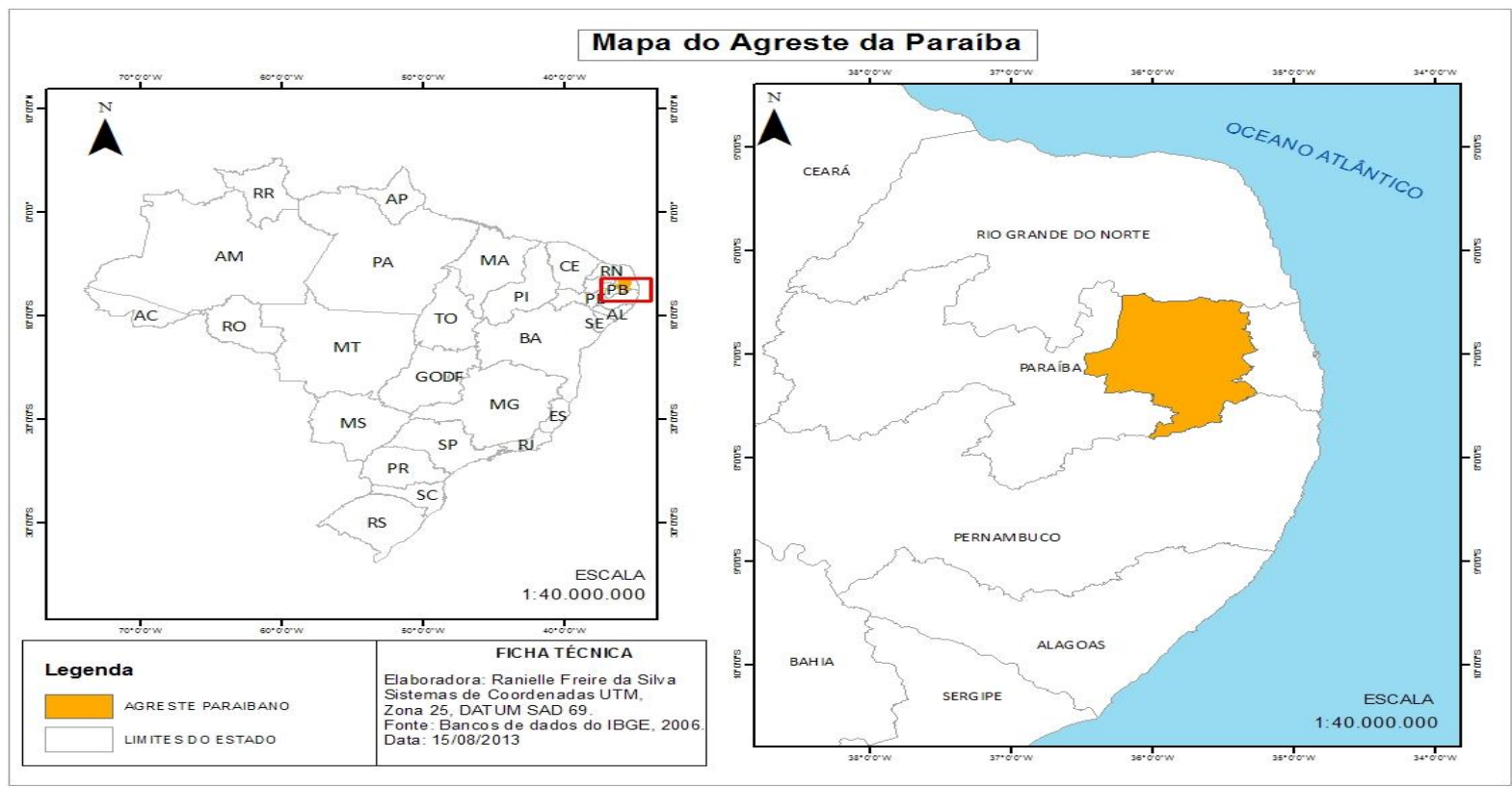

Fonte: IBGE (2006).

O Agreste da Paraíba constitui uma área fortemente individualizada quando são consideradas as formas de organização do espaço produtivo e, principalmente, as condições naturais que são marcadas pela heterogeneidade ambiental, tanto do ponto de vista espacial quanto temporal, sobretudo, quando se considera os seus parâmetros meteorológicos. Petersen, Silveira e Almeida (2002) ressaltam que, na dimensão tempo, a diversidade se manifesta em três níveis: sazonalidade climática bem definida, extrema variabilidade entre os totais pluviométricos anuais e, por fim, forte desuniformidade da distribuição da pluviometria total em um mesmo período chuvoso. No que se refere à dimensão espacial, os autores ressaltam que:

há diversidades bastante marcadas em dois níveis. No primeiro, numa escala de abordagem mais ampla e considerando a região como um todo, há forte contraste ambiental em curtas distâncias, proporcionado pela influência da serra da Borborema [...]. A Borborema interfere nos padrões de circulação atmosférica, gerando totais pluviométricos decrescentes de leste para oeste. No segundo nível, numa escala de abordagem local, há uma pronunciada variação nas características ambientais definida, sobretudo, por diferenças de solo [...]. A presença de horizontes pouco permeáveis na superfície (em diferentes profundidades) é quase marca geral 
nos solos das porções mais secas da região, proporcionando condições diferenciadas para infiltração e o armazenamento de água no solo, para o desenvolvimento vegetal, para a ocorrência de processos erosivos, etc. (PETERSEN; SILVEIRA; ALMEIDA, 2002, p. 21).

As condições ambientais, aliadas à sua posição geográfica de transição entre o litoral e o sertão paraibano, fazem com que a vegetação se apresente, espacialmente, de forma bastante diversificada. Nas áreas mais elevadas, comumente conhecidas como "Brejos de altitude", há a ocorrência da floresta tropical subperenifólia. Em direção aos contrafortes da Borborema, encontram-se a caatinga hipoxerófila e, na sequência, a caatinga hiperxerófila nas áreas próximas à Mesorregião da Borborema (PETERSEN; SILVEIRA; ALMEIDA, 2002). Nas áreas mais baixas dessa mesorregião, onde há maiores reservas hídricas, as espécies vegetais menos tolerantes ao estresse hídrico são mais favorecidas. Sendo assim, considera-se que essas características naturais conferem ao recorte espacial do estudo um aspecto bastante heterogêneo, ou seja, um mosaico de ambientes, fazendo com que seja possível a existência de potenciais muito diferenciados para a produtividade biológica.

A partir dessa contextualização, este estudo objetivou avaliar o estado de sustentabilidade de agroecossistemas de produção de mandioca (Manihot esculenta Crantz) situados no Agreste da Paraíba, utilizando o método do $S^{3}$ e sua representação gráfica, o Biograma.

\section{SUSTENTABILIDADE E AGROECOSSISTEMA: BREVES DISCUSSÕES TEÓRICAS}

Sustentabilidade (originário do latim sustentare, significando suster, suportar, conservar em bom estado, manter e resistir, etc.) é um dos termos dessa contemporaneidade prenhe de muitos sinônimos e combinações (SICHE et al., 2007) e que mais se difundiu, no decorrer dos últimos anos, a partir do encontro de Founex na Suíça, da Conferência das Nações Unidas sobre o Meio Ambiente, em Estocolmo, na Suécia, em 1972, e do encontro internacional The World 
Conservation Strategy (IUNC et al., 2011), apresentando diferentes definições e, sem dúvida, com focos distintos.

Entende-se sustentabilidade como sendo um objetivo final de um determinado desenvolvimento que pode ser suportado, mantido (SICHE et al., 2007) e, por isso, constitui-se num termo muito utilizado, de diversos sentidos e de poucas explicações e operacionalizações práticas. Contudo, não é consensual e varia conforme a área de atividade ou ambiente a que for aplicado (RIBEIRO et al, 1996; MÜLLER,1996). Mas, existe algo comum que é a capacidade de um sistema humano, natural ou misto, de permanecer ou de resistir à mudança endógena ou exógena por tempo indeterminado (DOVER; HANDMER, 1992). Ou seja, o termo em questão tem incorporado, na maioria das vezes, a articulação entre as dimensões social, econômica e ambiental, principalmente, embasando uma nova forma de desenvolvimento, que vai além da simples ideia de crescimento econômico a novas crenças, valores e parâmetros nas relações entre natureza e sociedade (GONÇALVES, 1996; SACHS, 2000; VEIGA, 2005; VAN BELLEN, 2007; CÂNDIDO, 2010). Assim, sustentabilidade constitui um termo dinâmico e complexo, substantivado por vários elementos, que parte de um sistema de valores com foco, ao longo do tempo, em múltiplas escalas. Por isso, torna-se praticamente impossível ter uma única definição. Mas, apesar da diversidade de termos e sentidos, parece existir certo grau de consenso sobre o mesmo em relação às necessidades de se reduzir a poluição ambiental, eliminar os desperdícios, diminuir o índice de pobreza e melhorar a qualidade de vida de indivíduos e sociedades (BARONI, 1992).

Entende-se que a sustentabilidade pode ser compreendida, também, como tudo aquilo que pode ser obtido, permanentemente, em condições semelhantes ou superiores de vida em dado ecossistema, objetivando a manutenção do sistema de suporte da vida. Ela pode ser relacionada a um melhor estado de qualidade de vida de populações em seus territórios vivenciais, a partir da capacidade de suporte dos ecossistemas. Essa qualidade de vida pode ser compreendida como o grau de prazer, satisfação e realizações socioeconômicas concretizados por cada indivíduo em seu cotidiano vivencial. A mensuração da sustentabilidade será possível mediante a definição e o uso de indicadores que significam, nas palavras de Sepúlveda (2008), aquelas 
variáveis que podem ser analisadas em cada dimensão e que se transformam na base de estimação da estrutura do $S^{3}$ ou Biograma.

Baseando-se nos fundamentos teóricos propugnados por Sepúlveda (2008) sobre o método $\mathrm{S}^{3}$ ou Biograma, a sustentabilidade deve contemplar uma visão mais abrangente - ou multidimensional e intertemporal - do desenvolvimento econômico, enfatizando, principalmente, o desenvolvimento sustentável de territórios rurais, como é o caso do estudo em pauta. Para o autor, o desenvolvimento econômico e o uso racional de recursos naturais estão, intimamente, relacionados às dimensões espaço-temporais. Na opinião do autor, o uso racional dos recursos naturais constitui um elemento fundamental de qualquer estratégia de desenvolvimento, não somente pela importância que tem para as gerações do presente e futuras mas, sobretudo, porque os recursos naturais constituem um dos ativos mais importantes do meio rural e, por conseguinte, dos agroecossistemas de produção agrícola (SEPÚLVEDA, 2008).

Por sua vez, o termo agroecossistema, que permeia a compreensão do trabalho em tela, está sendo considerado aqui como um múltiplo sistema de produção agrícola - uma propriedade ou uma lavoura em sua multidimensionalidade, por exemplo - compreendido como um ecossistema em suas múltiplas dimensões espaço-temporais, aproximando ao máximo da ecofisiologia do sistema natural, originando o termo agroecossistema (GLIESSMAN, 2009; ALTIERI, 2004). Esse termo expressa a compreensão de uma estrutura com a qual pode-se analisar os sistemas de produção de alimentos como um todo, incluindo seus conjuntos complexos de insumos, tecnologias e produção de transformação de ecossistemas e as interconexões que os compõem.

A constituição de um agroecossistema ocorre a partir do momento em que um dado ecossistema rural é alterado com o propósito de desenvolver uma dada produção agrícola, introduzindo várias mudanças na estrutura e função do ecossistema natural, mudando o estado inicial do sistema. As novas qualidades do sistema podem servir como indicadores de sustentabilidade do sistema, como assinalou Gliessman (2009). Para o autor, o agroecossistema constitui um recorte espacial de produção agrícola ou uma unidade territorial agrícola que envolve todos os organismos, sejam eles de interesse 
agropecuário ou não, considerando as inter-relações entre população, terra, comunidade ou ecossistema, tendo como prioridade a sustentabilidade.

Marques, Skorupa e Ferraz (2003), contribuindo com a discussão teórica deste estudo, definem agroecossistemas como sendo entidades territoriais ou regionais manejadas com o objetivo de produzir alimentos e outros produtos agropecuários, compreendendo elementos bióticos e abióticos em geral, incluindo agricultor e consumidor, com dimensões sociais, econômicas, ambientais e de saúde pública.

Além dessas ideias apresentadas, aglutina-se ao estudo em tela, os suportes teóricos propostos por Altieri (2004). Esse autor apresenta alguns aspectos importantes de um agroecossistema a serem considerados: é constituído por elementos bióticos e abióticos, ligados estreitamente, formando uma unidade ecológica funcional; possui limites definidos e qualidade de autorregulação; varia de acordo com a natureza de seus componentes ao arranjo tempo-espacial e, em relação ao nível de intervenção humana, constitui uma unidade territorial dependente e raramente tem limites biológicos bem definidos; além de pertencer a qualquer escala biogeográfica.

É a partir dessas perspectivas de agroecossistema, que envolvem elementos internos e fatores externos à unidade e à dinâmica de produção agrícola, que a temática da sustentabilidade do agroecossistema de produção de mandioca de base familiar do agreste paraibano procurou se embasar.

\section{SUSTENTABILIDADE DOS AGROECOSSISTEMAS DE MANDIOCA DO AGRESTE PARAIBANO: ELUCIDANDO OS CAMINHOS METODOLÓGICOS}

Os procedimentos metodológicos utilizados para a consecução do presente trabalho foram basicamente constituídos por levantamentos bibliográficos, leituras, fichamentos e análises de dados secundários obtidos em entidades pública e privada.

O método utilizado para a avaliação do desenvolvimento da produção de mandioca no Agreste da Paraíba foi o $\mathrm{S}^{3}$, ou Biograma, proposto por Sepúlveda (2008). Trata-se de um instrumento de representação teórico-gráfica que permite representar o estado de 
sustentabilidade de uma Unidade de Análise-UA, em um determinado período de tempo, utilizando-se de indicadores de diferentes Dimensões de Análises-DA. Segundo o autor, o Biograma, também denominado de teia de aranha, é complementado pelo estabelecimento do índice integrado de desenvolvimento sustentável ( $\mathrm{S}^{3}$ ), o qual permite avaliar o desempenho de uma unidade de análise (SEPÚLVEDA, 2008).

A escolha desse método, dentre os existentes sobre avaliação de sustentabilidade de agroecossistemas, ocorreu em virtude do $\mathrm{S}^{3}$, e/ou sua representação gráfica - o Biograma, ser uma metodologia que possibilita avaliações espaço-temporais comparativas, análises rápidas e universais de níveis de processo de desenvolvimento de territórios urbano ou rural diferentes, numa perspectiva multidimensional. Além de ser uma metodologia que dispõe de um programa de cálculo computadorizado.

Baseando-se nos passos metodológicos do $\mathrm{S}^{3}$, ou Biograma, selecionou-se a unidade de análise, representada por alguns recortes territoriais do Agreste da Paraíba, mais precisamente, pela realidade social de agroecossistemas de quatro municípios, a saber: Araçagi, Araruna, Bananeiras e Puxinanã. Em seguida, foram estabelecidas as dimensões de análise ambiental, econômica e social, contendo cada uma delas quatro indicadores. Após a seleção dos indicadores, foi definido o tipo de relação com o entorno, determinando a função de relação negativa (quando um aumento no valor do indicador agrava a situação do sistema), representada por 0 (zero) ou a função de relação positiva (quando o aumento no valor do indicador representa um avanço no sistema) de desenvolvimento do sistema agrícola, representada por 1 (um), tomando por base os aportes teóricos de Sepúlveda (2008).

O Quadro 1 mostra as dimensões, os indicadores e as respectivas unidades de medidas e relações com os níveis de desenvolvimento do sistema.

Quadro 1. Dimensões de Análises (DA), indicadores, unidades de medidas e Relação dos Indicadores (RI) com o desenvolvimento do sistema

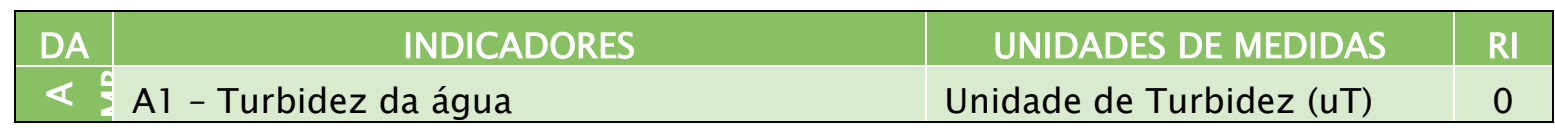




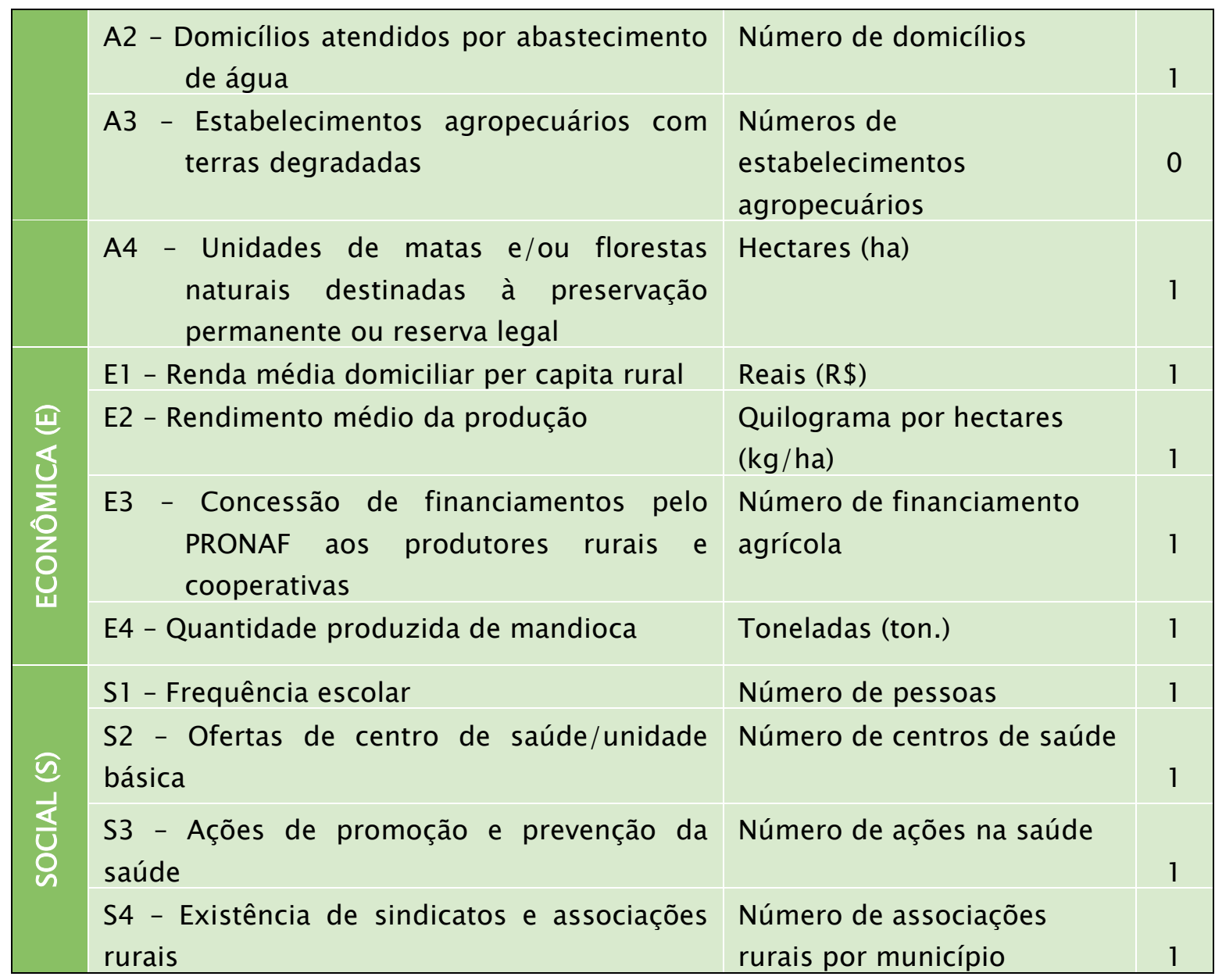

Fonte: BCB (2012); PARAIBA (2013); DATASUS (2010); IBGE (2006, 2010, 2011); FETAG (2012).

Os dados dessa avaliação de sustentabilidade foram coletados em diversas bases de informação, dentre as quais se sobressaiu o Instituto Brasileiro de Geografia e Estatística-IBGE, do qual foram levantadas informações sobre abastecimento de água nos domicílios, áreas de preservação permanente, número de estabelecimentos agropecuários com terras degradadas, renda domiciliar percapita, rendimento da produção de mandioca, valor da produção de mandioca e número de associações e sindicatos rurais. Foram utilizados, ainda, para coleta de dados secundários, informações do Departamento de Informática do Sistema Único de Saúde-DATASUS, sobre a quantidade de unidades básicas e de ações de promoção e prevenção à saúde. Do Programa Nacional de Fortalecimento Familiar-PRONAF, do Ministério do Desenvolvimento Agrário, foram obtidas informações a respeito do número de financiamentos concedidos aos agricultores e da Companhia 
de Águas e Esgotos da Paraíba-CAGEPA levantou-se dados em relação aos valores de turbidez da água.

A aplicação do método, segundo Sepúlveda (2008), ocorre pela definição da relação de cada indicador com a perspectiva de sustentabilidade e o cálculo de cada indicador. Conforme Sepúlveda (2008), para a obtenção do cálculo, duas fórmulas são utilizadas, visando relativizar os valores com o efeito sobre o entorno. No que se refere aos indicadores com relação direta (no qual o aumento do valor do indicador representa aumento da sustentabilidade), a fórmula para se calcular os indicadores é a seguinte.

$$
f(x)=\frac{x-m}{M-m}
$$

Para a situação de indicadores que apresentam uma relação inversa, com a finalidade de manter uma escala comum, utiliza-se esta fórmula:

$$
f(x)=\frac{x-M}{m-M}
$$

Em que:

$f(x)$ corresponde ao valor do índice para cada indicador (variando de 0 (zero) a 1 (um), em que o 1 representa a melhor situação de sustentabilidade.;

x é o valor de cada variável ou indicador para uma unidade de análise em um dado período;

m é o valor mínimo de cada indicador para um determinado período de tempo;

M é o valor máximo para cada indicador para um determinado período de tempo (SEPÚLVEDA, 2008).

Considerando os passos do $\mathrm{S}^{3}$, ou Biograma, convém ressaltar, ainda, que mediante a transformação de valores de indicadores em índices, é possível se mensurar o $\mathrm{S}^{3}$, que significa o agrupamento dos índices de todo sistema de cada unidade de análise (SEPÚLVEDA, 2008). Tal índice permite a visualização do estado geral de sustentabilidade do sistema avaliado, o qual pode variar entre 0 e 1 . Após a mensuração, é possível elaborar a representação gráfica do estado de sustentabilidade 
da unidade avaliada, seus aparentes desequilíbrios em cada dimensão, bem como os possíveis conflitos existentes.

No biograma, a identificação do estado de sustentabilidade da unidade de análise ocorre por meio da utilização de cinco cores, de acordo com cada índice (Quadro 2). Assim, quando a área do biograma for equivalente a um índice abaixo de 0,2, esse será representado pela cor vermelha que simboliza um estado de colapso. Para índices entre 0,2 e 0,4 , a representação é feita pela cor laranja, indicando uma situação crítica. Para os índices entre 0,4 e 0,6 a cor a ser utilizada é a amarela, representando uma situação instável; enquanto que os índices entre 0,6 e 0,8 serão representados pela cor azul, simbolizando um sistema estável e, por fim, entre os índices de 0,8 e 1, a cor a ser considerada é a verde, indicando uma situação ótima no tocante à sustentabilidade do sistema, conforme pode ser visualizado pelo Quadro 2.

Quadro 2. Relação entre o estado do sistema, os índices e as cores do Biograma

\begin{tabular}{|c|c|c|c|c|}
\hline $\begin{array}{c}\text { Colapso } \\
\mathrm{S}^{3}<2\end{array}$ & Crítico & Instável & Estável & Ótima \\
\hline
\end{tabular}

Fonte: Adaptado de Sepúlveda (2008).

\section{AVALIANDO A SUSTENTABILIDADE DOS AGROECOSSISTEMAS DE MANDIOCA DO AGRESTE PARAIBANO}

A avaliação de sustentabilidade dos agroecossistemas de produção de mandioca do Agreste da Paraíba tem sido realizada de maneira comparativa entre os agroecossistemas dos quatro municípios investigados, tendo como referências os valores mínimo e máximo encontrados entre as referências de sustentabilidade que configuram os cinco estados, indicados no Quadro 2. Os valores apresentados nos quadros e tabelas foram transformados em índices e agregados nas suas respectivas dimensões, e ilustrados pelo Biograma. Inicialmente, definiu-se como UA a área territorial da Mesorregião do Agreste paraibano, representada por agroecossistemas de quatro municípios que mais se destacaram na produção de mandioca, tanto na 
mesorregião quanto no Estado da Paraíba. Os municípios selecionados foram os de Araçagi (Microrregião Guarabira), Araruna (Microrregião Curimataú Oriental), Bananeiras (Microrregião Brejo Paraibano) e Puxinanã (Microrregião Campina Grande).

Para permitir uma comparação entre os territórios, optou-se por apresentar os resultados por UAs. Sendo assim, observou-se que os agroecossistemas, situados nos municípios do agreste paraibano, apresentaram na dimensão ambiental, no que se refere ao indicador turbidez da água (A1), melhores resultados nos municípios de Bananeiras (2,20 uT), Araruna (2,24 uT) e Araçagi (2,34 uT) e o pior resultado em Puxinanã (2,88 uT), segundo informações da Companhia de Água e Esgotos da Paraíba-CAGEPA (PARAíBA, 2013). Quanto à quantidade de domicílios atendidos por abastecimento de água (A2), os localizados em Araruna apresentaram melhores condições, contando com 3.096 domicílios atendidos, seguido pelos municípios de Bananeiras, com 2.789 e de Araçagi, com 2.384. Já os situados em Puxinanã aparecem com menores números, possuindo somente 2.196 domicílios atendidos com abastecimento de água, segundo informação do Censo Demográfico (IBGE, 2010).

No tocante aos estabelecimentos agropecuários com terras degradadas (A3), os agroecossistemas localizados em Araçagi apresentaram melhores condições, com apenas quatro estabelecimentos agropecuários com terras degradadas, seguido pelo Município de Puxinanã, com 20 estabelecimentos degradados. Dentre os agroecossistemas que se apresentaram com o maior número de estabelecimentos com terras degradadas foram os dos municípios de Araruna e Bananeiras, possuindo ambos 35 estabelecimentos degradados (IBGE, 2011).

No que se refere à quantidade de unidades de matas nativas destinadas à preservação permanente e reserva legal (A4), o Município de Bananeiras apresenta-se em situação melhor que os demais, por possuir uma área de 672 hectares destinados à vegetação nativa, seguido pelos de Araçagi, com 466 hectares e de Araruna, com 208 hectares. Em Puxinanã está a pior situação, haja vista dispor de apenas 18 hectares reservados à preservação da mata nativa, conforme dados disponíveis no Censo Agropecuário (IBGE, 2006). 
Em relação ao indicador renda domiciliar per capita rural (E1), integrante da dimensão econômica, os dados obtidos mostraram que a maior renda foi encontrada entre os agroecossistemas dos municípios de Puxinanã ( $R \$ 226,00$ ), seguido por Araçagi ( $R \$ 178,00)$ e Bananeiras (R\$ 172,00), e a menor renda domiciliar rural encontrou-se nos agroecossistemas do Município de Araruna, ficando em torno de R\$ 157,00 (IBGE, 2006). No que se refere ao rendimento médio da produção de mandioca em quilogramas por hectares (E2), os dados evidenciaram que os municípios de Araçagi e Puxinanã apresentaram os melhores resultados, com rendimentos de 12.000 e $10.000 \mathrm{~kg} / \mathrm{ha}$, respectivamente. Por outro lado, os piores resultados de rendimentos da produção de mandioca ocorreram entre os municípios de Araruna e Bananeiras, ficando em torno de 6.545 e $8.000 \mathrm{~kg} / \mathrm{ha}$, respectivamente. Com relação à quantidade produzida de mandioca (E3), constatou-se que as maiores produções ocorreram nos agroecossistemas de Puxinanã, com a produção de 21.000 toneladas de mandioca, Araçagi produziu 18.600 toneladas, seguido por Bananeiras, que teve uma produção de 7.200 toneladas. O Município de Araruna (com produção de 3.600 toneladas de mandioca) apresentou o pior desempenho no que se refere a essa variável, segundo dados fornecidos pela Produção Municipal Agrícola (IBGE, 2011). Quanto aos números de financiamentos agrícolas concedidos aos produtores rurais (E4), a maior quantidade foi destinada aos agroecossistemas de Bananeiras (com cerca de 279 financiamentos), seguido por Araçagi (com 79 financiamentos) e Araruna (com 41 financiamentos). Os menores números de financiamentos agrícolas ocorreram em Puxinanã, com apenas 14 financiamentos agrícolas (BCB, 2012).

No que tange à dimensão social, o indicador frequência escolar (S1), apresentou os seguintes resultados: Bananeiras e Araruna possuem os maiores números de pessoas comparecendo às escolas (7.505 e 6.782 pessoas respectivamente), seguido por Araçagi (5.202 pessoas) e Puxinanã (4.099 pessoas), conforme dados do Censo Demográfico (IBGE, 2011). Já em relação ao número de centros de saúde (S2), percebeu-se que os municípios do agreste paraibano apresentam quantidade de unidades de saúde semelhantes, sendo observados os melhores resultados em Bananeiras (que possui 9 unidades), Araçagi e Araruna (ambos com 8 unidades). Enquanto que o menor número de 
unidades de saúde foi observado no Município de Puxinanã (conta com apenas 3). No que tange à quantidade de ações de promoções e prevenção à saúde (S3), o melhor resultado foi encontrado no Município de Araçagi, com 68.927 ações de atendimento, seguido dos municípios de Araruna, com 63.501, e de Bananeiras, com 61.694 ações de saúde. Já o Município de Puxinanã apresenta o menor número em ações de saúde (23.954), conforme informações disponibilizadas no DATASUS (BRASIL, 2010). Além disso, quanto à participação dos agricultores em associações e sindicatos rurais, verificou-se a ausência dessas associações nos municípios de Bananeiras e Puxinanã e a presença dessa representação social nos municípios de Araçagi e Araruna (IBGE, 2006; FETAG, 2012).

A partir da mensuração dos indicadores selecionados, pode-se observar que dos 12 indicadores selecionados, o Município de Araçagi, apresentou resultados com índices de sustentabilidade ótimos em cinco indicadores (A3, E2, E3, S3 e S4), com índices de valores entre 0,9 e 1,0, estáveis em três indicadores (A1, A4 e S2), que apresentarem índices com valores entre 0,7 e 0,8 e críticos em quatro indicadores (A2, E1, E4 e S1), com índices entre 0,0 e 0,3 , conforme os parâmetros de comparação e os intervalos dispostos no Quadro 2.

Com relação ao Município de Araruna, a avaliação dos indicadores expressou a seguinte situação: quatro indicadores de sustentabilidade (A1, A2, S3 e S4) foram considerados ótimos por terem apresentado índices entre 0,9 e 1,0, dois indicadores da dimensão social (S1 e S2) apresentaram índices estáveis com valores iguais a 0,8, um indicador da dimensão ambiental (A4) apresentou nível crítico, com índice igual a 0,3 e cinco indicadores, sendo quatro deles da dimensão econômica e um da dimensão ambiental (E1, E2, E3, E4 e A3) apresentaram nível de colapso com índices iguais a 0,0 .

A análise de sustentabilidade do Município de Bananeiras evidenciou que cinco indicadores (A1, A4, E4, S1 e S2) obtiveram índices ótimos com valores iguais a 1,0. Apenas dois indicadores (A2 e S3) apresentaram índices estáveis de sustentabilidade, com valores entre 0,7 e 0,8 , respectivamente. Três indicadores da dimensão econômica (E1, E2 e E3) apresentaram índices críticos de sustentabilidade, com valores variando entre 0,2 e 0,3 e dois indicadores (A3 e S4) 
apresentaram índices com valores iguais a 0,0, caracterizando nível de colapso.

Quanto à realidade socioeconômica e ambiental do Município de Puxinanã, os resultados são de que oito indicadores (A1, A2, A4, E4, S1, S2, S3 e S4) apresentaram índices em estado de colapso, dos quais quatro fazem parte da dimensão social; outro apresentou situação crítica, com índice igual a 0,2 e integra a dimensão econômica (E2). Além desses, dois outros indicadores, pertencentes à dimensão econômica (E1 e E3), demonstraram estado ótimo de sustentabilidade, com valor 1,0 e o último indicador, da dimensão ambiental, apresentou índice instável de sustentabilidade, com valor igual a 0,5.

A Tabela 2 apresenta de maneira sintética os resultados dos índices de cada indicador, bem como o índice integrado de sustentabilidade $\left(\mathrm{S}^{3}\right)$, da situação dos agroecossistemas de cada do município do agreste paraibano.

Tabela 2. Dimensão, indicadores e índices da situação dos agroecossistemas dos municípios do Agreste da Paraíba

\begin{tabular}{|c|c|c|c|c|c|}
\hline DIMENSÕES & INDICADORES & ARAÇAGI & ARARUNA & BANANEIRAS & PUXINANÃ \\
\hline AMBIENTAL & $\mathrm{A} 1$ & 0,8 & 0,9 & 1,0 & 0,0 \\
\hline \multirow[t]{3}{*}{ (A) } & A2 & 0,2 & 1,0 & 0,7 & 0,0 \\
\hline & A3 & 1,0 & 0,0 & 0,0 & 0,5 \\
\hline & A4 & 0,7 & 0,3 & 1,0 & 0,0 \\
\hline ECONÔMICA & El & 0,3 & 0,0 & 0,2 & 1,0 \\
\hline \multirow[t]{3}{*}{ (E) } & E2 & 1,0 & 0,0 & 0,3 & 0,2 \\
\hline & E3 & 0,9 & 0,0 & 0,2 & 1,0 \\
\hline & E4 & 0,0 & 0,0 & 1,0 & 0,0 \\
\hline SOCIAL & S1 & 0,3 & 0,8 & 1,0 & 0,0 \\
\hline \multirow[t]{3}{*}{ (S) } & S2 & 0,8 & 0,8 & 1,0 & 0,0 \\
\hline & S3 & 1,0 & 0,9 & 0,8 & 0,0 \\
\hline & S4 & 1,0 & 1,0 & 0,0 & 0,0 \\
\hline \multicolumn{2}{|c|}{ INDICE INTEGRADO (\$3) } & 0,7 & 0,5 & 0,6 & 0,2 \\
\hline
\end{tabular}

Fonte: Elaborado pelos Autores (2013).

Ao final da avaliação, verificou-se que os agroecossistemas apresentaram índices integrados de sustentabilidade de 0,7 para a realidade social dos agroecossistemas do município de Araçagi, 0,6 para os agroecossistemas do município Bananeiras, 0,5 para os 
agroecossistemas do município de Araruna e 0,2 para os agroecossistemas do município de Puxinanã.

A figura 2 ilustra a situação de sustentabilidade em que se encontram os agroecossistemas de produção de mandioca dos municípios investigados. De acordo com os resultados, o Biograma evidencia o estado geral de sustentabilidade, bem como o desequilíbrio entre os indicadores avaliados, revelado também pela diferença entre o índice integrado de desenvolvimento sustentável (S3), obtido por cada agroecossistema de produção de mandioca da Mesorregião do Agreste Paraibano (Figura 2). 
Figura 2. Biograma da situação de sustentabilidade dos agroecossistemas de municípios do Agreste da Paraíba

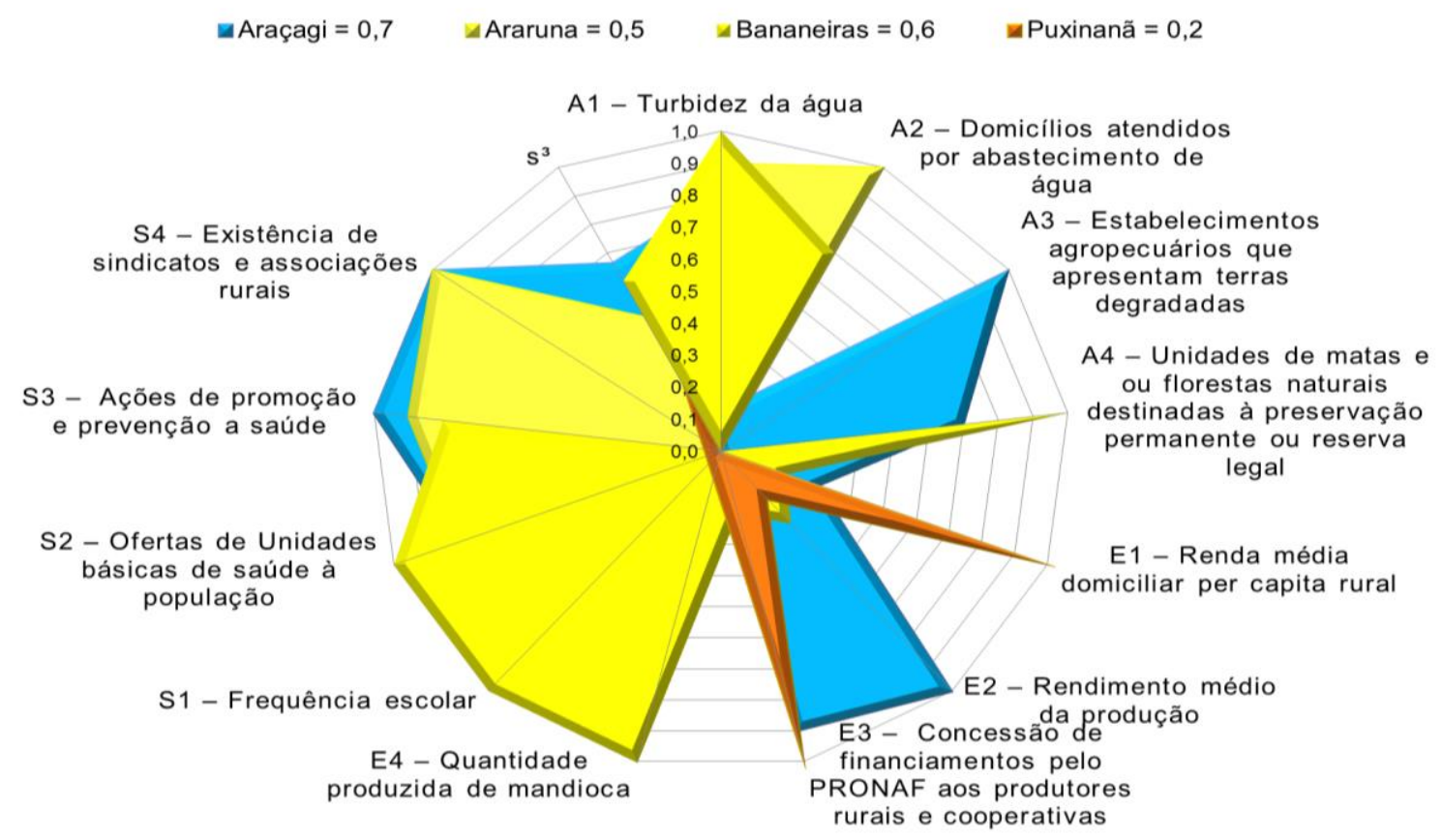

Fonte: Elaborado pelos Autores (2013).

Esse biograma possibilita uma melhor visualização dos distintos padrões de sustentabilidade dos agroecossistemas e, por conseguinte, de alguns municípios do agreste paraibano, representando, graficamente, o estado atual dos sistemas em um determinado ponto no tempo. Essa demonstração gráfica constitui uma radiografia momentânea da realidade socioeconômica e ambiental da produção de mandioca do agreste paraibano, porém, não expressa as trajetórias percorridas ou as dinâmicas territoriais da produção milenar dessa cultura agrícola. Além disso, os distintos níveis ou padrões de desenvolvimento territorial, representados pelos índices e pela operacionalização do método $\mathrm{S}^{3}$ ou Biograma, auxiliam na percepção e na compreensão dos processos de desenvolvimento, dos aparentes desequilíbrios entre as dimensões, assim como dos possíveis conflitos existentes.

Analisando as informações desse biograma, pode-se afirmar que o Município de Araçagi apresentou um estado de sustentabilidade estável (índice igual a 0,7), sendo considerado o de melhor estado de sustentabilidade dentre os demais municípios produtores de mandioca 
do agreste paraibano avaliados. No entanto, pode-se perceber que, nos agroecossistemas desse município, os indicadores A2, E1, E4 e S1 apresentaram índices iguais ou bem próximos de zero. Os municípios de Bananeiras e Araruna apresentaram um estado de sustentabilidade instável (índices iguais a 0,6 e 0,5, respectivamente). Os indicadores econômicos, representados por E1, E2, E3 e E4, do Município de Araruna, apresentaram índices iguais a zero, caracterizando uma situação de desequilíbrio na dimensão econômica do agroecossistema. Já os indicadores do Município de Bananeiras, que se destacaram por apresentar índices com valores iguais ou próximos de zero, foram os indicadores A2, E1, E2, E3 e S4. Por fim, o Município de Puxinanã apresentou um estado de sustentabilidade crítico (índice igual a 0,2) nessa avaliação de sustentabilidade. Essa situação crítica de sustentabilidade deu-se em virtude de que esse município apresentou índices iguais a zero em grande parte de seus indicadores, principalmente, nos indicadores da dimensão social e ambiental, impactando, significativamente, na permanência da produção de mandioca e, por conseguinte, na prosperidade da maioria das pessoas residentes nesse município.

\section{CONCLUSÃO}

Após o término da avaliação da sustentabilidade da produção de mandioca de municípios do agreste paraibano, utilizando o $S^{3}$ ou o biograma, conclui-se que os municípios avaliados evidenciaram os seguintes estados de sustentabilidade: estável para o Município de Araçagi, instável para os municípios de Araruna e Bananeiras e, por fim, crítico para o Município de Puxinanã. Desse modo, afirma-se que a produção de mandioca nos agroecossistemas dos municípios de maior produção do estado da Paraíba tem se apresentado, de modo geral, com situações insustentáveis quanto aos níveis de uso de inovação tecnológica, ao rendimento médio da produção de mandioca, à situação de terras em processo erosivo, à escassez de água e à ausência de participação social. Esses têm sido os maiores problemas dos agroecossistemas de produção de mandioca do Agreste da Paraíba.

Convém ressaltar que, diante dos resultados expostos, os agroecossistemas avaliados necessitam melhorar seus estados de 
sustentabilidade, uma vez que a agricultura, para ser sustentável, deve conservar os recursos ambientais, garantir a justiça social e ser viável economicamente, garantindo, assim, a produção agrícola e a qualidade de vida das presentes e futuras gerações.

Por fim, considera-se que este trabalho pode se constituir numa fonte de conhecimento da realidade socioeconômica e ambiental de agroecossistemas de produção de mandioca, bem como, para a identificação dos desequilíbrios e das fragilidades em relação ao uso e a conservação dos recursos naturais, a participação social e a forma de produção existente em cada território avaliado, visando melhorias tanto na forma de produção agrícola quanto na busca por uma agricultura estável e sustentável. Além do mais, as representações proporcionadas pelo biograma podem levar a diferentes formas de intervenção pública e privada na busca de processos sustentáveis de desenvolvimento da cultura da mandioca e de territórios envolvidos com suas produções.

\section{REFERÊNCIAS}

ALMEIDA, M. A; SANTOS, E. S. Análise comportamental do agronegócio da mandioca (Manihot esculenta) no Brasil de 2004 a 2009. João Pessoa. Revista Tecnologia e Ciência Agropecuária, v.5, n.2, p. 41-49, 2011.

ALTIERI, M. Agroecologia: bases científicas para uma agricultura sustentável. Rio de Janeiro, RJ: Ed. Agropecuária, 2004.

BARONI, M. Ambiguidades e deficiências do conceito de desenvolvimento sustentável. Revista de Administração de Empresas, São Paulo, v.32, n.2, p.14-24, abr./ jun. 1992.

BCB - BANCO CENTRAL DO BRASIL. Anuário estatístico do credito rural 2012. Disponível em: <http://www.bcb.gov.br/htms/CreditoRural/2012/rel525.pdf $>$. Acesso em: 28 mai. 2013.

BRASIL. Ministério da saúde. Departamento de informática do SUS. Informações de saúde, Esplanada dos Ministérios, mai. 2013. Disponível 
em: <http://www2.datasus. gov.br/DATASUS/index.php>. Acesso em: 10 mai. 2013.

CÂNDIDO, G. A. Desenvolvimento sustentável e sistemas de indicadores de sustentabilidade: formas de aplicações em contextos geográficos diversos e contingências específicas. Campina Grande: Ed. UFCG, 2010.

COSTA, A. A. V. M. R. Agricultura sustentável III: indicadores. Revista de Ciências Agrárias, Lisboa, v. 33, n. 2, dez. 2010. Disponível em: $<$ http://www.scielo.mec.pt/scielo.

php?pid=S0871-018X2010000200009\&script=sci_arttext $>$. Acesso em: 20 mar. 2012

DOVERS, S. R.; HANDMER, J. W. Uncertainty, sustainable development: defining urban social sustainability. Sustainable Development, v. 19, n. 5, p. 289-300, 2011.

EHLERS, E. O que é agricultura sustentável. São Paulo: Brasiliense, 2008.

FETAG - FEDERAÇÃO DOS TRABALHADORES NA AGRICULTURA DO ESTADO DA PARAÍBA. Sindicatos, João Pessoa, dez. 2010. Disponível em: $<$ http://www.fetagpb.org. br/sindicatos2.php >. Acesso em: 25 mar. 2013.

GLIESSMAN, S. R. Agroecologia: processos ecológicos em agricultura sustentável. Porto Alegre: Ed. Universidade/UFRGS, 2009.

IBGE - INSTITUTO BRASILEIRO DE GEOGRAFIA E eSTATÍstiCA. Censo agropecuário 2006. Disponível em: <http://www.ibge.gov.br/home/ estatistica/ economia/agropecuaria / censoagro/ default.shtm >. Acesso: 25 abr. 2013.

- Censo Demográfico 2010. Disponível em: $<$ http://www.cidades.ibge. gov. br/ xtras $/$ temas.php?lang $=\&$ codmun $=250080$ \&idtema $=20$ \&searc $\mid$ pesquisanacional-de-saneamento-basico-2008 >. Acesso em: 25 abr. 2013. 
Produção agrícola municipal 2011. Disponível em:

http://www.sidra.ibge.gov.br/bda/acervo/acervo9.asp?e $=c \& p=P A \& z=t \&$ $0=11$

Acesso em: 20 jan. 2013.

IUCN; UNEP; WWF. The world conservation strategy. living resource conservation for sustainable development. International Union for Conservation of Nature (IUCN), United Nations Environment Programme (UNEP) and World Wide Fund for Nature (WWF), Gland, Switzerland, 1980.

LORENZI, J.O. Cultura da mandioca. Campinas: CATI - Coordenadoria de Assistência Técnica Integral, 2003. 116p. (CATI. Boletim Técnico, 245).

MARQUES, J. F.; SKORUPA, L. A.; FERRAZ, J. M. G. Indicadores de sustentabilidade em agroecossistemas. Jaguariúna, SP: Embrapa Meio Ambiente, 2003.

MICHELS, I; CARVALHO, M. C; MENDONÇA, C. G. Mandioca. Campo Grande: UFMS, 2004. 190 p.

MÜLLER, S. ¿Cómo medir la sostenibilidad?: una propuesta para el área de la agricultura y de los recursos naturales. San Jose, Costa Rica: GTZIICA, 1996. 56 p. (Série Documentos de Discusión sobre Agricultura Sostenible y Recursos Naturales, 1).

PARAíBA. Companhia de Água e Esgoto da Paraíba. Disponível em: $<$ http://www. cagepa.pb.gov.br/qualidade/list_analises_publico.php >. Acesso em: 15 mai. 2013.

PETERSEN, P.; SILVEIRA, L.; ALMEIDA, P. Ecossistemas naturais e agroecossistemas tradicionais no Agreste da Paraíba: uma analogia socialmente construída e uma oportunidade para a conservação agroecológica. In: SILVEIRA, L.; PETERSEN, P.; SABOURIN, E. (Org.) Agricultura familiar e agroecologia no semiárido: avanços a partir do agreste da Paraíba. Rio de Janeiro: AS-PTA, p. 13-25, 2002. 
PORTO-GONÇALVES, C. W. Geografia política e desenvolvimento sustentável, Terra Livre, São Paulo, n. 11-12, p. 9-76, 1996.

RIBEIRO, W. C. et al. Desenvolvimento sustentável: mito ou realidade, Terra Livre, São Paulo, n. 11-12, p. 77-90, ago.92/ago.93, 1996.

SACHS, I. Caminhos para o desenvolvimento sustentável. São Paulo: Garamond, 2000, 95 p.

SEPÚLVEDA S. S. Biograma: metodología para estimar el nivel de desarrollo sostenible de territorios. San José, C.R.: IICA, 2008.

SICHE, R. et al. Índices versus indicadores: precisões conceituais na discussão da sustentabilidade de países. Ambiente \& Sociedade, v. 10, n. 2, p. 137-148, jul./dez. 2007.

VAN BELLEN, H. M. Indicadores de sustentabilidade: uma análise comparativa. Rio de Janeiro: FGV, 2007.

VEIGA, J. E. da. Desenvolvimento sustentável: o desafio do século XXI. Rio de Janeiro: Garamond, 2005.

Submetido em 19/09/2013

Aprovado em $08 / 07 / 2015$

Sobre os autores

Valdenildo Pedro da Silva

Doutor em Geografia pela UFRJ, Instituto Federal do Rio Grande do Norte.

Endereço: Avenida Senador Salgado Filho, 1559, Tirol. 59015-000 - Natal - RN - Brasil.

E-mail: valdenildo.silva@ifrn.edu.br.

Leci Martins Menezes Reis

Doutora em Recursos Naturais pela UFCG, Instituto Federal do Rio Grande do Norte. Endereço: Avenida Senador Salgado Filho, 1559, Tirol. 59015-000 - Natal - RN - Brasil. E-mail: leci.reis@ifrn.edu.br

Anieres Barbosa da Silva 
Doutor em Ciências Sociais pela UFRN. Professor da Universidade Federal da Paraíba, Centro de Ciências Exatas e da Natureza.

Endereço: Campus I, Departamento de Geociências. Cidade Universitária, Castelo

Branco. 58059-900 - Joao Pessoa - PB - Brasil.

E-mail: anieres@uol.com.br.

\section{Ranielle Freire da Silva}

Tecnóloga em Gestão Ambiental pelo IFRN, Instituto Federal do Rio Grande do Norte.

Endereço: Avenida Senador Salgado Filho, 1559, Tirol. 59015-000 - Natal - RN - Brasil.

E-mail: ranyfreire@hotmail.com 